\title{
The RISC-KIT storm impact database: A new tool in support of DRR
}

\author{
P. Ciavola ${ }^{\mathrm{a}, *}$, M.D. Harley ${ }^{\mathrm{b}}$, C. den Heijer ${ }^{\mathrm{c}, \mathrm{d}}$ \\ a Department of Physics and Earth Sciences, University of Ferrara, Ferrara, Italy \\ ${ }^{\mathrm{b}}$ Water Research Laboratory, School of Civil and Environmental Engineering, UNSW Sydney, Manly Vale, NSW, Australia \\ ${ }^{\mathrm{c}}$ Deltares, Delft, The Netherlands \\ ${ }^{\mathrm{d}}$ Delft University of Technology, Faculty of Civil Engineering and Geosciences, Delft, The Netherlands
}

\section{A R T I C L E I N F O}

\section{Keywords:}

Coastal storms

Database

Historical storminess

OpenEarth

Europe

\begin{abstract}
A B S T R A C T
This paper presents a new storm impact database for European coastlines that facilitates the upload, browsing and download of a broad range of physical and impact information related to historical and recent marine storm events. The database is transparent in terms of open access to raw data and metadata, makes use of version control systems through the OpenEarth repository and promotes the use of international standards. A total of 298 storm events are currently stored in the database from the ten RISC-KIT case study sites, including historical events dating back to the sixteenth century. To demonstrate the application of the tool, examples of typical event data contained within the database as well as the ability of the database to identify impacts of events across regions are presented. It is envisaged that this database will expand beyond the ten case study sites, with the aim of promoting and greatly improving the collection and reporting of extreme hydro-meteorological events across Europe into the future.
\end{abstract}

\section{Introduction}

A key first step in the disaster risk reduction (DRR) chain is the understanding of the present and historic context of an area in terms of past and current hazards and their associated impacts (Twigg, 2015). With regards to extreme hydro-meteorological events, information about the location, timing and severity of the event and how this impacts society and the environment as a whole are crucial to decision makers and coastal managers alike, enabling them (among other things) to raise risk awareness, identify trends, locate critical "hot-spot" areas and uncover common issues between regions (Van Dongeren et al., 2014). This information can in turn be used to assess coastal risk for present and future hazard probabilities and ultimately lead to better-designed DRR plans (Van Dongeren et al., 2017).

A large amount (>terabytes) of observational (e.g. tides, waves, winds), hindcast and reanalyses data of marine events, such as ERA-40 (Uppala et al., 2005), NCEP (National Center for Environmental Prediction) and HIPOCAS (Hindcast of Dynamic Processes of the Ocean and Coastal Areas of Europe (Sotillo et al., 2006)), are available in raw format, but require data pre-processing to extract key forcing variables related to individual marine events for a specific coastal area (e.g., Harley et al., 2010). Likewise, information with regards to the impacts of marine events is often routinely collected (but stored locally) by government agencies such as local geological services, reinsurers, in media reports and academic studies. However, there are currently very few tools available to provide detailed and readily-available information relating the environmental forcing conditions of a marine event to their subsequent impacts. Furthermore, impacts have mostly been assessed in terms of economic losses and loss of life without taking into account the broader social, cultural and environmental aspects that are critical to DRR considerations (Martinez et al., 2017). One of the most advanced examples of such a tool is the SurgeWatch database built by Haigh et al. (2015) for the United Kingdom. The database is simple to use, readily accessible and contains data for a long time span of almost 100 years. The SurgeWatch database however is a national example, while the focus here is on a European scale.

Several European Union (EU) funded projects have made inroads into the development of an impact-oriented marine storm database for the European coastline. The EU Fourth Framework Program (FP4) project CODECS (COoperative ITS DEployment Coordination Support) established a database of instrumental records for the past 300 years, and qualitative information for the past 1000 years, but was restricted to the European Atlantic coast, between $37^{\circ} \mathrm{S}$ and $58^{\circ} \mathrm{N}$ (Betts et al., 2004; Dawson et al., 2004; Lozano et al., 2004). During the EU Sixth Framework Program (FP6), the HYDRATE Project (Hydrometeorological Data Resources And Technologies for Effective flash flood forecasting

\footnotetext{
* Corresponding author.

E-mail addresses: cvp@unife.it (P. Ciavola),m.harley@unsw.edu.au (M.D. Harley), kees.denheijer@deltares.nl, c.denheijer@tudelft.nl (C. den Heijer).
} 


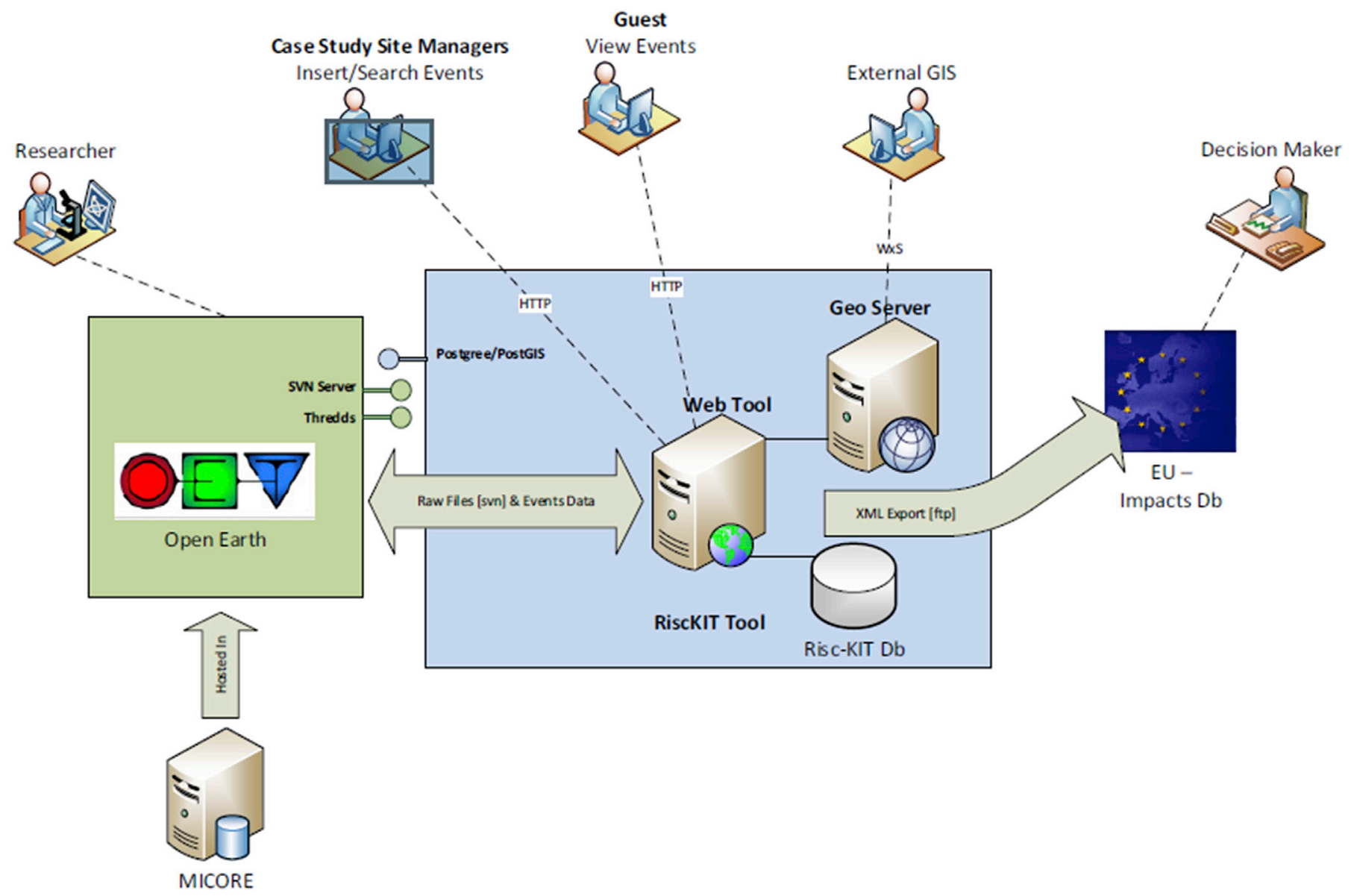

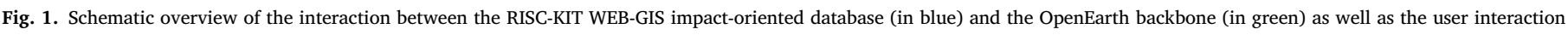
with it. (For interpretation of the references to colour in this figure legend, the reader is referred to the web version of this article.)

a)

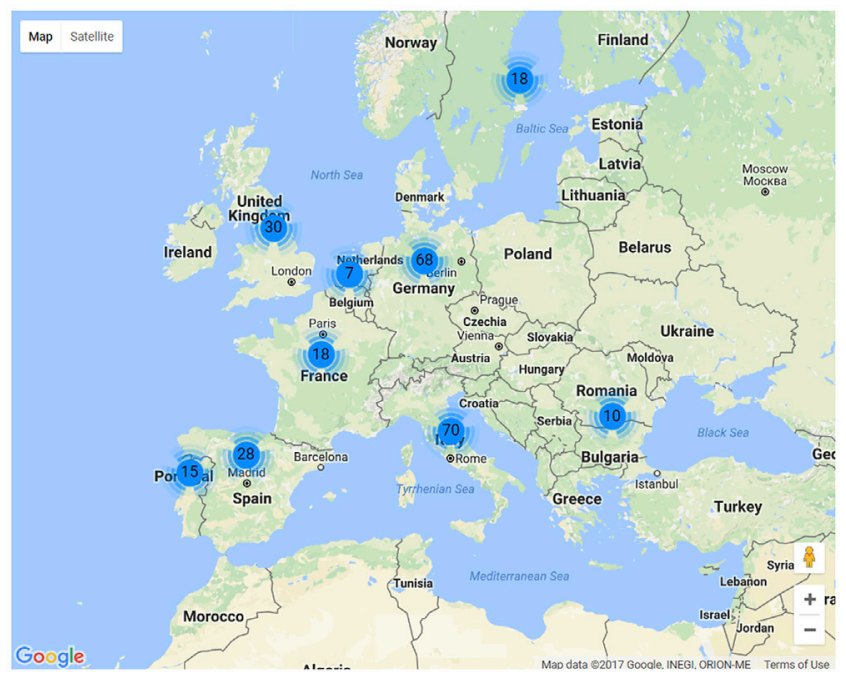

b)

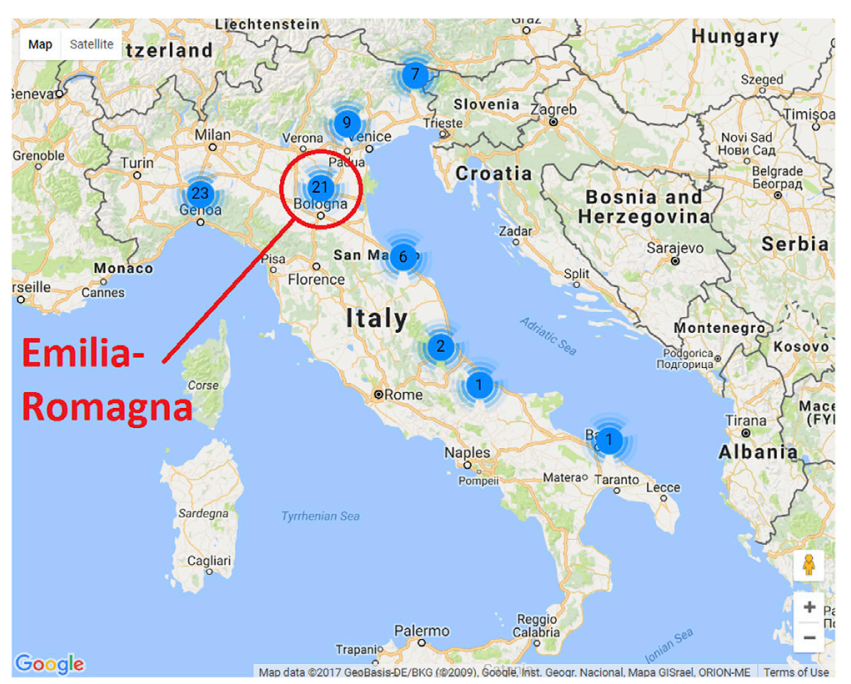

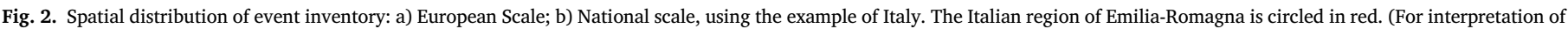
the references to colour in this figure legend, the reader is referred to the web version of this article.)

attempted a similar exercise at a European scale (six member states) for flash floods. In a recent paper Porcu and Carrassi (2009) linked events recorded based on ERA-40 reanalysis data with the MRNat-Cat archive by the Munich Re reinsurance company for all weather-induced disasters in the period 1992-1996. Their approach is interesting as they managed to identify the damage by cyclonic systems, but remains rather confined to a short time period of only several years.

In the EU Seventh Framework Program (FP7) project MICORE (Morphological Impacts and Coastal Risks induced by Extreme storm events), a database of marine storms and their impacts was assembled for nine case study sites across Europe and hosted on the open-source OpenEarth repository at Deltares, The Netherlands. A review of 
a)

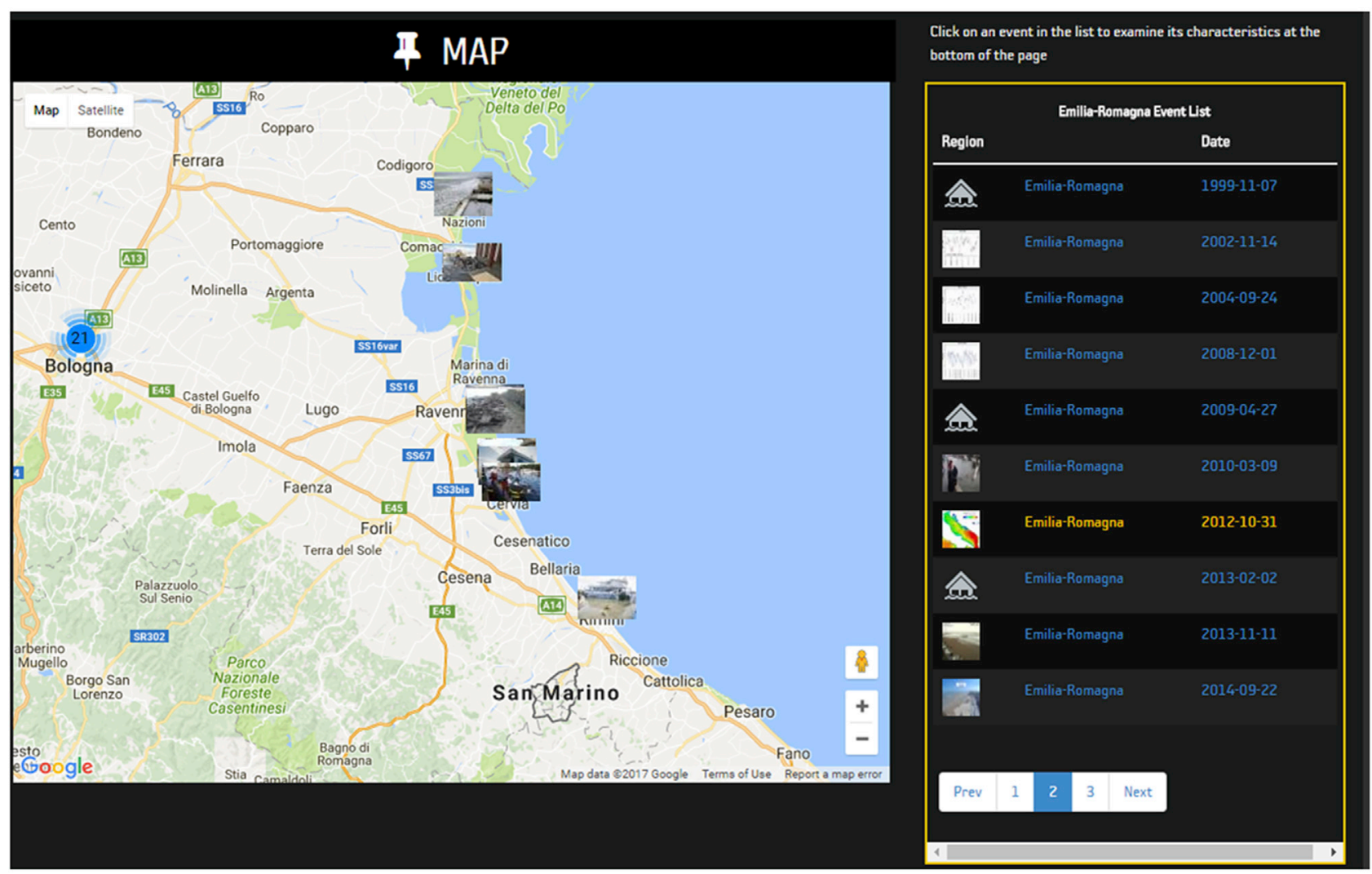

b)

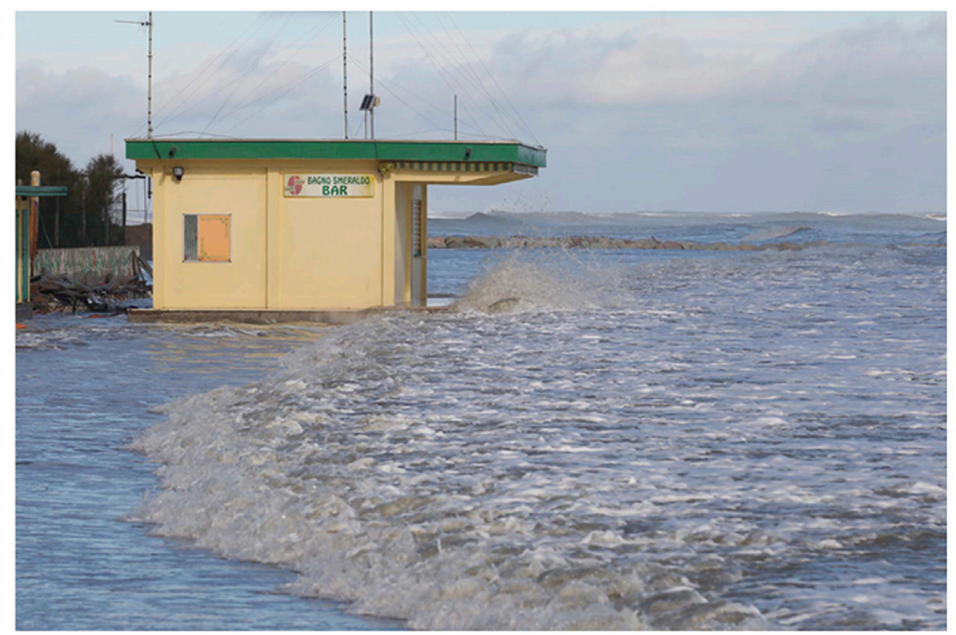

c)

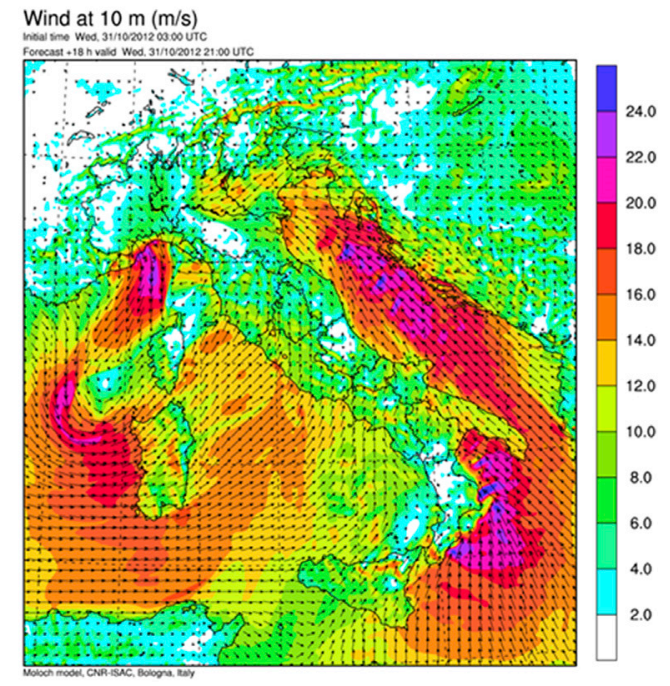

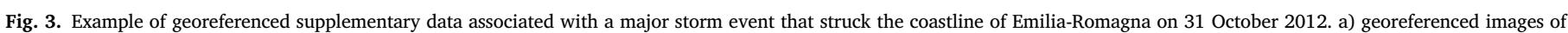

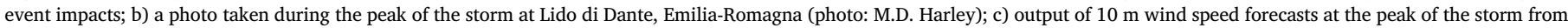
the CNR MOLOCH model.

existing data and literature on marine storm impacts in Europe (nine member states) was then undertaken by the MICORE partnership that lead to a historical storm report edited by Ferreira et al. (2009) as well as a number of scientific publications, see Ciavola et al. (2011) and Ciavola and Jiménez (2013) for a review. The assembled dataset included all forcing data, the morphological response, as well as impacts such as physical damages, economic losses and lives lost or number of people injured. An analysis of the existing coastal planning schemes was made in order to identify what actions are planned in each European country to reduce vulnerability and increase coastal resilience (Ferreira et al., 2009). Information on the entire regional coastline for each partner country was also integrated.

The databases produced by the MICORE and HYDRATE projects were data driven as they only included events where instrumental data were available. The RISC-KIT project progresses beyond that knowledge, using physical information for both marine storms as well as flash floods that specifically generated an impact on coastal areas, through the expansion towards historical (i.e. pre twentieth century) sources and the inclusion of socio-economic information on the events (Garnier et al., 2017; Martinez et al., 2017). Where possible, measured physical parameters (waves, winds, precipitation, river and sea water levels) have been used for event characterization, integrated with hindcast information for 
winds and waves derived from the likes of ERA-40 and HIPOCAS reanalyses datasets. No specific criteria in terms of the number and types of data fields to be collected were however adopted over the course of the MICORE project, meaning that the data are often site-specific, not georeferenced and lack homogeneity between sites. This therefore limits functionality in terms of the ability to perform database queries and intersite comparisons through a simple WEB-GIS interface, restricting its broader use amongst decision makers and coastal managers across Europe.

With these considerations in mind, the RISC-KIT (Resilience Increasing Strategies for Coasts - ToolKIT) project deemed it a matter of urgency that a new WEB-GIS tool be developed that facilitates the standard upload of impact-oriented data of marine storm events collected for each of the ten RISC-KIT case study sites.

The social and economic aspects of post disaster appraisal was examined as well as cultural and, if necessary, health related aspects like type of casualties occurred during and after the event. This approach is not new and was started by the FP7 Kulturisk project (http://www. kulturisk.eu/results/wp2) but only focused on sea-level rise, flash floods and marine flooding not considering other coastal threats like damage to coastal infrastructures or occurrence of extreme coastal erosion leading to failure of the first line of defence (dykes or dunes). The database compiled in the RISC-KIT project integrates data from the different hazards (storms, surges, winds, coastal flooding) in a systematic way, also providing historical data. An example of the potential of this approach is the analysis presented in the paper by Garnier et al. (2017).

This tool has the following goals:

- To collect physical, geographical and impact information about events through a standard web interface

- To integrate any related existing stored data at the case study sites, such as those collected in site-specific format during the MICORE database

- To incorporate historical (including pre-twentieth century) data and stakeholder interview information collected during the RISC-KIT project

- To promote use of collected data by the research community dealing with DRR

- To give users access to collected data through an easy-to-use web user interface and open-source protocols

- To promote adoption of a European framework to collect likewise information

- To improve the reporting of future events

The database is publicly available at the address http://risckit. cloudapp.net/risckit/\#/.

The aim of this paper is to provide the technical details of the database construction as well as information on the choices made for including events in the database. In the following section, the materials and methods related to the database design are described. This is followed by an example of the datasets contained for one of the RISC-KIT case study sites located in Italy on the northern Adriatic Sea (the Emilia-Romagna coastline). A discussion on how the database can be used by the DRR community and others is then presented.

\section{Materials and methods}

In this section the characteristics of the database as well as the methods for data intake are summarised.

\subsection{Database design}

The WEB-GIS impact-oriented database has four main functions:

1) Upload of storm event data and metadata

2) Viewing of storm event data and metadata
3) Web services $(\mathrm{WxS})$ for reuse of the storm event data and metadata 4) $\mathrm{Xml}$ export to $\mathrm{EU}$ impacts database

In the design, a key priority was the integration of RISC-KIT data with existing data and analysis tools collected from previous and ongoing projects, including the MICORE database of marine storms. To that end, the OpenEarth platform (Van Koningsveld et al., 2010) is used as a backbone. OpenEarth provides a Version Control System (VCS, subversion repository) for raw data (https://svn.oss.deltares.nl/repos/ openearthrawdata/). Access is possible with an account, which is available to anyone upon request (http://oss.deltares.nl/). The VCS provides transparency in the sense that it is clear what data is added/changed by whom and when this occurred. The OpenEarth approach is to store processing scripts, to produce well-documented data products, with the raw data (in VCS) in order to make the data products reproducible and transparent. OpenEarth adopted among others the netCDF (Network Common Data Form, https://doi.org/10.5065/D6H70CW6) format, being a set of self-describing, machine-independent data formats that support the creation, access, and sharing of array-oriented scientific data. OpenEarth provides a THREDDS data server (TDS, https://doi.org/10. 5065/D6N014KG) to serve the well-documented data products in netCDF format at http://opendap.deltares.nl/thredds.

The RISC-KIT specific WEB-GIS impact-oriented database is dedicated to provide a user friendly environment for upload and viewing of storm event (meta)data.

The WEB-GIS impact-oriented database has been set up with the following components (Fig. 1):

1) A central database (PostgreSQL with PostGIS extension)

2) A web application

3) A GeoServer installation

The web application provides a user interface (website) that can make sure that the ingested data is uniform across all case study sites and stores data files in the OpenEarth raw data VCS without requiring the user to know anything about VCS. The web application stores georeferencing information in the PostgreSQL database as well, for performance reasons and for interaction with the GeoServer.

Data ingested via the RISC-KIT web application are assigned the following OpenEarth file structure:

https://svn.oss.deltares.nl/repos/openearthrawdata/trunk/ $<$ institution_name $>/$ risckit/raw $/<$ Event_ID $>/$

where:

Institution_name $=$ the name of the institution providing/ingesting the data.

Event_ID = identification of the event according to Country, Region and event start date.

The institution name is used at the highest level in order to clearly show the first point of contact for underlying datasets. One level deeper, all RISC-KIT are bundled in one directory "risckit", which could be seen as one dataset with a number of events in it. By convention, OpenEarth uses for each dataset a subdirectory raw for bundling of the raw (meta) data, in this case a series of events distinguished by event_ID.

Metadata associated with raw data (data ownership, data quality, instrument location, etc.), is managed in the database using the INSPIRE metadata standard (http://inspire.ec.europa.eu/). For every raw file, an INSPIRE metadata file (in xml format) is encouraged to be uploaded. This can be undertaken using the INSPIRE metadata editor available from the INSPIRE website.

\subsection{Event upload interface}

Data upload is undertaken by registered data managers on an eventby-event basis for each site by filling in a number of standardised data fields related to the event. The use of standardised fields thereby ensures data is stored in a uniform way and facilitates intersite comparisons and 
database queries. A minimum amount of mandatory information is required for each event to be stored in the database, namely the country and region of the storm event (as defined using Eurostats NUTS nomenclature), the event start date, as well as a brief description of the event (for example, synoptic type of the event, the name of the storm, unique characteristics related to the event etc.). Event data for the database is divided into three main data types discussed below: 1) Physical Data; 2) Impact Data; and 3) Supplementary Data.

\subsubsection{Physical data}

Physical data related to the event include the country and region where the event occurred, the timing of the event (i.e., start date and event duration) as well as key pieces of physical information associated with the event's intensity. In the database, event intensity information is represented by data fields of relevant statistics of wave height (mean/ peak significant wave height, wave direction), water levels (maximum total water level or astronomical tide) and/or wind speeds (mean/peak wind speed or gust, wind direction). Where applicable, an option to enter inland/river flooding data related to the event, such as peak discharge or flood heights, is also included. Metadata associated with this information (e.g. instrument type, location, data manager) is encouraged to be uploaded using the INSPIRE standardised format as described in Section 2.1.

\subsubsection{Impact data}

A key initiative of this database is the linking of physical data with a broad spectrum of impact information. Similar to the reporting format adopted by the EU Floods Directive (European Commission, 2013) six different impact categories are used to classify this range of impact data. These impact categories are: Economy; Population; Buildings and private property; Environment; Infrastructure; and Cultural heritage. Within each of these categories are a number of sub-categories that enable further more-refined classification of the impact type. The impact sub-categories are as follows:

1) Economy - Manufacturing; Government; Retail and services; Tourism; Construction; Fishing; Mining; and Other

2) Population - Deaths during event; Total deaths (including long-term); Evacuated during event; Missing; Permanently relocated; Injured; Loss of employment; and Other
3) Buildings and private property - Residential houses; Apartment blocks; Farm houses; Shops/restaurants/tourist buildings; Hotels/ hostels; Boats and other watercraft; Camping sites; and Other

4) Environment - Habitats; Pollution; Protected areas; Water quality for drinking or irrigation; Water quality for bathing; Biodiversity; Flora and Fauna; and Other

5) Infrastructure - Coastal and hydraulic structures; Ports and harbours; Hospitals and aged care facilities; Road networks; Train networks; Public administration; Schools; Utilities (Electricity, gas, water supply, telecommunications); and Other

6) Cultural heritage - Art works; Museums; Monuments and memorials; Historical and architectural heritage sites; Religious/spiritual places; Archaeological sites; Libraries and archives; and Other

Once the category and sub-category are defined, the user is then prompted to insert a number of fields to further describe the impact. Where applicable, this includes a qualitative description of the impact, a quantitative description involving some unit of impact measure (e.g. number of building damaged, number of hours out of service, number of victims, number of hectares flooded) and the total cost of the impact in a specified currency. An unlimited amount of impacts can be added to the database for each event. Based on all impacts added, a total impact cost is crudely estimated using a simple summation.

\subsubsection{Supplementary data}

The final data type that can be uploaded and stored in the database relates to supplementary information. Supplementary information can be either in the form of media files (e.g. archival photos or footage, newspaper reports, stakeholder interview recordings, data figures) or geospatial GIS information (e.g. shapefiles). The value of documentary information from newspapers should not be underestimated, as proved for floods in the Catalan territory by Llasat et al.(2009). In this case the authors did not approach the issue of geo-referencing as the database is simply based on the articles. A slightly more advanced approach, specifically targeted towards marine storms, was that of Ribera et al. (2011) who matched information extracted from regional and local Spanish newspapers with the HIPOCAS-derived storm database. In the RISC-KIT database a step forward was made by requiring all supplementary information to be geo-referenced, date stamped and briefly described.

Table 1

Description of socio-economic impacts entered into the data for a storm that struck the coastline of Emilia-Romagna (Northern Italy) on 31 October 2012.

\begin{tabular}{|c|c|c|c|c|}
\hline Impact category & Impact sub-category & Description & Unit of measure & Total cost \\
\hline Environment & Habitats & $\begin{array}{l}\text { Dune erosion in the natural area between Lido di Classe and Lido di Dante. } \\
\text { The dune to the south of Lido di Dante in particular becomes critically } \\
\text { reduced, leaving just a very small dune to protect the pine forest behind }\end{array}$ & $\begin{array}{l}2 \mathrm{~m} \text { of dune retreat at } \\
\text { Lido di Dante South (as } \\
\text { measured by SGSS beach } \\
\text { profile surveys) }\end{array}$ & Null \\
\hline Buildings and private property & $\begin{array}{l}\text { Shops/restaurants/ } \\
\text { tourist buildings }\end{array}$ & $\begin{array}{l}\text { Bagno Patti at Milano Marittima damaged beyond repair. Damage } \\
\text { estimated at } 80000 \text { euro (according to Romagna Noi article, 22/11/ } \\
\text { 2012) }\end{array}$ & $\begin{array}{l}1 \text { bathing establishment } \\
\text { destroyed }\end{array}$ & $€ 80,000$ \\
\hline Environment & Habitats & $\begin{array}{l}\text { Overwash of the dune between the Reno River mouth and the Bellocchio, } \\
\text { with marine ingression up to the inland levee protecting the Lido di Spina } \\
\text { camping site }\end{array}$ & $\begin{array}{l}45 \mathrm{~m} \text { of dune retreat (as } \\
\text { measured by SGSS } \\
\text { Emilia-Romagna profile } \\
\text { surveys) }\end{array}$ & Null \\
\hline Infrastructure & $\begin{array}{l}\text { Coastal and hydraulic } \\
\text { structures }\end{array}$ & $\begin{array}{l}\text { Structures protecting the Gorino lighthouse are damaged, } 30000 \text { euro in } \\
\text { intervention requested }\end{array}$ & Null & $€ 30,000$ \\
\hline Buildings and private property & Camping sites & Partial flooding of Camping Rubicone, Savignone Mare & $\begin{array}{l}\text { Unknown number of } \\
\text { hectares flooded }\end{array}$ & Null \\
\hline Infrastructure & Road networks & $\begin{array}{l}\text { In the center of Lido di Savio, marine water floods roads for up to } 1 \mathrm{~km} \\
\text { inland, causing road closures and sand deposits }\end{array}$ & Null & Nul \\
\hline Environment & Coastal erosion & $\begin{array}{l}\text { Around } 6 \mathrm{~km} \text { of coastline between Lido di Volano and Lido di Spina } \\
\text { suffering erosion. }\end{array}$ & $\begin{array}{l}120,000 \mathrm{~m}^{3} \text { of sand } \\
\text { eroded from beach }\end{array}$ & $€ 1,300,000$ \\
\hline Infrastructure & $\begin{array}{l}\text { Coastal and hydraulic } \\
\text { structures }\end{array}$ & post-storm nourishment and restoration of wooden groins at Lido di Spina & Null & $€ 500,000$ \\
\hline Buildings and private property & $\begin{array}{l}\text { Boats and other } \\
\text { watercraft }\end{array}$ & $\begin{array}{l}\text { Fishing boat sinks in canal at Cervia, subsequently refloated using a crane } \\
\text { the day after by the Fire Department (cost unknown) }\end{array}$ & 1 fishing boat sinks & Null \\
\hline Environment & Habitats & $\begin{array}{l}\text { A new inlet forms at the Sacca di Goro, with potential damage to the } \\
\text { brackish ecosystem }\end{array}$ & 1 new inlet formed & Null \\
\hline
\end{tabular}


3. Results: overview based on datasets present

At the time of writing, the database contained 298 reported storm events, with the highest coverage in Italy (70 reported events), followed by Germany ( 66 events) and the UK ( 29 events). It is important to note that the database is intended to be a "living database" beyond the life of the RISC-KIT project, with data upload continuing when new data become available. The current data coverage comprising the RISC-KIT case study sites can be seen at a European and national scale in Fig. 2.

As mentioned previously, a key initiative of the RISC-KIT database is the inclusion of pre-twentieth century events obtained from historical sources (Garnier et al., 2017), in addition to more modern event data contained in this and existing databases. Some notable examples of historical events stored in the RISC-KIT database include a storm in 1566 in Gotland, Sweden that wrecked 15 warships and is considered one of the greatest maritime disasters in the Baltic Sea; a storm in Liguria, Italy in
1613 that also caused the sinking of a dozen ships and is commemorated by an engraving in the harbour of Genoa; and a 1840 storm in the Algarve, Portugal whose destructive effects are depicted in a local religious painting. Other pre-twentieth century events include storms in 1625 (Germany), 1665 (UK), 1705 (Emilia, Romagna, Italy), 1711 (France) and 1777 (Spain).

3.1. An example of database content and usage at regional level from the Emilia-Romagna coastline

To demonstrate the contents of the database for a specific location and how an end-user could potentially benefit from this tool, an example is presented here for the RISC-KIT case study region of Emilia-Romagna coastline in Northern Italy. The Emilia-Romagna coastline suffers from repeated flooding and the regional government has consequently been developing a practical approach for the estimation of flood vulnerability
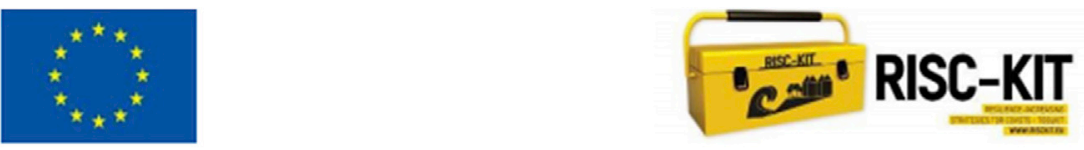

\title{
Event Fact Sheet
}

\begin{tabular}{|l|l|}
\hline EVENT: & $31-10-2012$ \\
\hline Country: & ITALIA \\
\hline Region: & Emilia-Romagna \\
\hline
\end{tabular}

\begin{abstract}
Description
The "Halloween storm": On the night of the 31 December 2012, south-easterly (Scirocco) winds resulted in a strong storm surge event in the northern Adriatic Sea. Water levels peaked at $1.16 \mathrm{~m}$ at Ravenna, the equal highest level recorded in 15 years of water level measurements at Ravenna and equivalent to a 1-in-20 to 1-in-50 year event. These extreme water levels caused widespread flooding along the entire Emilia-Romagna coastline, damaging beachfront buildings and resulting in the loss of sections of natural dunes. A subsequent storm on the 11 November further damaged the already vulnerable coastline.
\end{abstract}

\section{Physical Data}

\begin{tabular}{|l|l|}
\hline General Information & \\
\hline Start Date: & $31-10-2012$ \\
\hline Start hour: & $08: 00$ \\
\hline Duration: & 15 hour(s) \\
\hline Wave Information & \\
\hline Wave height: & $\begin{array}{l}2.43 \text { (meters) (Peak significant wave } \\
\text { height) }\end{array}$ \\
\hline Wave direction: & 87.00 Degrees from N \\
\hline Wind Information & \\
\hline Wind intensity: & $\begin{array}{l}15.50 \text { (meters/sec) (Maximum wind } \\
\text { speed) }\end{array}$ \\
\hline Wind direction: & \\
\hline Water Information & 1.16 (meters) (Maximum total water \\
\hline Value: & level) \\
\hline Peak water discharge: & Not relevant \\
\hline Flood height: &
\end{tabular}

\section{Impacts}

\begin{tabular}{|l|l|}
\hline Category: & Environment \\
\hline Sub category: & Habitats \\
\hline Description: & $\begin{array}{l}\text { Dune erosion in the natural area } \\
\text { between Lido di Classe and Lido di } \\
\text { Dante. The dune to the south of Lido di } \\
\text { Dante in particular becomes } \\
\text { criticallyreduced, leaving just a very } \\
\text { small dune to protect the pine forest } \\
\text { behind }\end{array}$ \\
\hline
\end{tabular}

Fig. 4. Example of an event fact sheet (first page only) that can be readily exported from the database as an easy-to-read pdf for use by the DRR community. 
(Perini et al., 2016) which could be applied in the future for coastal planning (Sekovski et al., 2015).

A total of 21 events are currently in the database for the EmiliaRomagna region (refer Fig. 2b). The chosen example is a storm that occurred on 31 October 2012. The storm is commonly referred to as the "Halloween Storm" (owing to the storm's occurrence during the night of Halloween) and was caused by intense south-easterly winds that produced extreme water levels reaching a maximum of $1.16 \mathrm{~m}$ above mean sea level at 23:30 GMT at the Ravenna tide gauge. According to previous authors (Harley et al., 2016) this is typical of a 1-in-20- to 1-in-50-year event. Measurements of significant wave heights $\left(\mathrm{H}_{\mathrm{s}}\right)$ at the Cesenatico wave buoy peaked $2.43 \mathrm{~m}$ at 03:00 GMT on the 1 November 2012. When waves are considered in isolation to the extreme water levels they represent only a relatively minor storm event for this coastline and insufficient in generating large bathymetric changes (Armaroli and Ciavola, 2011) or consistent dune erosion (Armaroli et al., 2012). On the other hand, the combined exceedence of wave height and surge level thresholds predicts for this coastline inundation and damage to infrastructures (Armaroli et al., 2012).

A series of geo-referenced images depicting impacts across the EmiliaRomagna region due to the Halloween storm are displayed upon clicking on the event in the website event list panel (Fig. 3a and b). These images have predominantly been sourced from local newspapers, publicallyavailable webcams adjacent to the coastline and personal photographs, with the original source of all images clearly described in the supplementary metadata. Also included in the supplementary data are relevant output figures of forcing data associated with this event, for example forecasts of $10 \mathrm{~m}$ wind speeds at the peak of storm from the CNR MOLOCH forecast model (Fig. 3c).

Table 1 presents the reported socio-economic data for the Halloween storm, using the appropriate categories and sub-categories outlined in Section 2.2.2. Regional impacts for this storm ranged from significant beach and dune erosion, disruption to road networks due to marine flooding and damage (and, in some cases, complete destruction) of infrastructure and watercraft. It can be seen in Table 1 that several of these impacts reported in the database resulted in estimated economic losses for the region, ranging from 30,000 euros to in excess of one million euros. Other impacts, such as a new inlet forming in a wetland ecosystem due to the storm, however remain difficult to cost and hence the Total Cost column is left empty.

For a complete summary of all physical and impact data, an option is provided on the website to download an "Event Fact Sheet", as indicated in Fig. 4 (first page shown only). This fact sheet is downloadable as an Adobe pdf file and presents all event information (including uploaded images of impacts and other figures) in a concise manner for use by the DRR community and others. For greater transparency, raw data and metadata used to calculate the event physical data (e.g., peak significant wave height) can also be downloaded from the Open-Earth repository. In the case of the Halloween storm, this comprises wave and water-level time-series measurements from the Ravenna tide gauge and Cesenatico wave buoy for the time period encapsulating the storm event. Metadata including the instrument locations, instrument types and data managers are contained within the corresponding INSPIRE metadata file.

\subsection{Examples of database usage to identify common impacts across European countries}

Another example of the benefits of the database is the ability to track events across several European regions, such as the 2010 "Xynthia" storm that passed across the Iberian Peninsula and the western coast of France. According to the reconstruction of the meteorological setting of this extreme event provided by Bertin et al. (2012), the weather system hit the northern coast of Portugal on the morning of 27 February 2010 with wind speeds of $15-20 \mathrm{~m} / \mathrm{s}$. It subsequently struck the French coast in the southern Bay of Biscay during the night of 28 February 2010, reaching wind speeds of $45 \mathrm{~m} / \mathrm{s}$. During the day it moved towards Belgium and
Germany with wind speed dropping down to $10-15 \mathrm{~m} / \mathrm{s}$. An analysis of the database, which reports storms with documented damages, finds no impact for the study regions in Portugal (Algarve). On the contrary the French department Vendée (at La-Faute-sur-Mer) suffered 29 casualties as well the department of Charente-Maritime suffered 12 casualties. Widespread damages on the economy, private properties and infrastructures are also reported correctly. No records are present from Belgium as well none are present for Germany as the study region is located in Baltic Sea, which was not affected by the storm.

A further example where an event can be tracked across two countries occurred on 5-6 December 2013 when a storm comparable to the Great North Sea Flood of 1953 hit the coast of East Anglia in the United Kingdom as well as the West-Flanders of Belgium (Spencer et al., 2015). The event is correctly reported for both member countries, with a global damage of 14 milion euros for the Belgian coast and detailed damage description for the economy, private properties, ecosystems and infrastructures in East Anglia.

\section{Discussion: how the database can be used by the DRR community}

An example of the benefits of the coastal storm database can be found in the paper by Garnier et al. (2017), where the authors managed to undertake a study of historical storminess and impacts using event information made available in the database. In the paper above, the authors provide an analysis of frequency of occurrence for the case studies in Portugal, France, Italy and the United Kingdom, proving that in the French and Italian sites a lack of "historical memory" has exposed the population to the impact of events which have happened several times, despite the public opinion and decision makers have labelled them as "exceptional". Likewise Pfister et al. (2010), reconstructed the meteorological framework and the cultural memory of three severe winter-storms in early eighteenth-century Europe using historical records. In a recent paper Bulteau et al. (2015) demonstrated how historical information can improve estimation and prediction of extreme coastal water levels, taking as example the area hit by the Xynthia storm in France. Another interesting work is that of (Camuffo et al., 2000), who made an extensive long-term climatological reconstruction from the sixteenth century to the present day for the northern Adriatic. Data collection was carried out by searching in public and private libraries and archives for 20 years. Similarly (Lamb and Frydendahl, 1991) produced an almost 600 years old reconstruction of historic storms in the North Sea, British Isles, and Northwest Europe.

The understanding of the human and financial costs caused by past events will ultimately lead to a better understanding of the stakes and vulnerabilities of the case study sites in a long-term perspective ( $>200$ years) and will strengthen prevention and preparation strategies for extreme events. In addition, the knowledge gained can provide examples with regards to the memory of risks, which will serve as useful tools for mediation with elected representatives and local communities.

A fundamental goal of the database is to provide a framework for the reporting of extreme hydro-meteorological events in the future, in order to improve the way in which physical and impact data in particular are collected. A common observation made by case study site managers during the collection of data for the 298 (currently) uploaded events is that impact data is best obtained immediately following the event and that, when left too long, is often too reliant on less-accurate newspaper reports rather than more primary sources (such as those collected by experienced practitioners). By already providing the data fields and impact categories required for event reporting, site managers are better prepared for data collection should an event occur.

One may question how this tool can be further developed into the future. In terms of database expansion, the option of crowdsourcing data from the general community is compelling. This however would require a careful quality control of this information in order to avoid the insertion of spurious information that could de-value the database as a whole. One 
could imagine that only authorised users, with a minimum of training in disaster response from both the physical and socio-economic aspects should be allowed to report the events. Local coastal managers are for example the ideal subjects of this action as they could report to a central office in the administration, where database managers could validate the information. This type of action is currently being undertaken as a prototype in the Emilia-Romagna region, where the InStorm Database has been developed for internal use by the Regional Government (L. Perini pers. comm.) for the planning of flood defence maintenance as well as beach replenishments.

\section{Conclusions}

Knowledge of the magnitude, frequency and impacts of prior extreme hydro-meteorological events for a particular coastal site or region is critical to designing and implementing effective disaster risk reduction plans. While a number of databases of historical storm events currently exist across Europe, they have on the whole been of limited applicability for the European DRR community and more broadly. This is predominantly due to the fact that they are restricted in spatial extent to the local or regional scale, only cover a modern time period spanning several years, lack homogeneity in the type of information collected and do not cover the complete spectrum of social, environmental and economic impact information that is necessary for effective DRR design.

The new RISC-KIT storm impact database presented here makes significant developments from previous efforts by providing the following benefits:

1) A standardised data upload protocol for event reporting at the European scale;

2) A user-friendly web interface for the browsing and downloading of uploaded event information;

3) Use of a transparent version control system (VCS) for raw data and metadata storage;

4) Limited technical know-how required for the upload of event data (e.g. ingested data is stored in VCS but does not require the user to have technical knowledge about VCSs);

5) Categorization of event impact information into a wide range of social, environmental and economic impacts in close alignment with the EU Flood Directives reporting system;

6) Inclusion of historical information of extreme events dating back to the sixteenth century;

7) Inclusion of geo-referenced images of impacts as well as relevant figures of forcing conditions (such as reanalyses dataset outputs)

At the time of writing the database contained nearly 300 events across the ten RISC-KIT case study sites, from which common forcing conditions, impact issues and trends across these different regions could be readily identified. It is hoped that this new database will continue to grow beyond the case study sites as it is adopted by the European DRR community and others, with the aim of promoting and greatly improving the collection and reporting of extreme hydro-meteorological events across Europe into the future.

\section{Acknowledgements}

This work was supported by the European Community's 7th Framework Programme through the grant to RISC-KIT ("Resilience-increasing Strategies for Coasts - Toolkit"), grant no. 603458, and by contributions by the partner institutes.

\section{Appendix A. Supplementary data}

Supplementary data related to this article can be found at https://doi. org/10.1016/j.coastaleng.2017.08.016.

\section{References}

Armaroli, C., Ciavola, P., 2011. Dynamics of a nearshore bar system in the northern Adriatic: a video-based morphological classification. Geomorphology 126, 201-216. http://dx.doi.org/10.1016/j.geomorph.2010.11.004.

Armaroli, C., Ciavola, P., Perini, L., Calabrese, L., Lorito, S., Valentini, A., Masina, M., 2012. Critical storm thresholds for significant morphological changes and damage along the Emilia-Romagna coastline, Italy. Geomorphology 143-144. http:// dx.doi.org/10.1016/j.geomorph.2011.09.006.

Bertin, X., Bruneau, N., Breilh, J.F., Fortunato, A.B., Karpytchev, M., 2012. Importance of wave age and resonance in storm surges: the case Xynthia, Bay of Biscay. Ocean. Model 42, 16-30. http://dx.doi.org/10.1016/j.ocemod.2011.11.001.

Betts, N.L., Orford, J.D., White, D., Graham, C.J., 2004. Storminess and surges in the South-Western Approaches of the eastern North Atlantic: the synoptic climatology of recent extreme coastal storms. Mar. Geol. 210, 227-246. http://dx.doi.org/10.1016/ j.margeo.2004.05.010.

Bulteau, T., Idier, D., Lambert, J., Garcin, M., 2015. How historical information can improve estimation and prediction of extreme coastal water levels: application to the Xynthia event at la Rochelle (France). Nat. Hazards Earth Syst. Sci. 15, 1135-1147. http://dx.doi.org/10.5194/nhess-15-1135-2015.

Camuffo, D., Secco, C., Brimblecombe, P., Martin-Vide, J., 2000. Sea storms in the adriatic sea and the western mediterranean during the last millennium. Clim. Change 46, 209-223. http://dx.doi.org/10.1023/A:1005607103766.

Ciavola, P., Ferreira, O., Haerens, P., Van Koningsveld, M., Armaroli, C., 2011. Storm impacts along European coastlines. Part 2: lessons learned from the MICORE project. Environ. Sci. Pol. 14, 924-933. http://dx.doi.org/10.1016/j.envsci.2011.05.009.

Ciavola, P., Jiménez, J.A., 2013. Preface the record of marine storminess along European coastlines. Nat. Hazards Earth Syst. Sci. http://dx.doi.org/10.5194/nhess-13-19992013.

Dawson, A., Elliott, L., Noone, S., Hickey, K., Holt, T., Wadhams, P., Foster, I., 2004. Historical storminess and climate "see-saws" in the North Atlantic region. Mar. Geol. 210, 247-259. http://dx.doi.org/10.1016/j.margeo.2004.05.011.

European Commission, 2013. Guidance for Reporting under the Floods Directive ( 2007/ 60/EC ). Brussels.

Ferreira, Ó., Ciavola, P., Armaroli, C., Balouin, Y., Benavente, J., Del Río, L., Deserti, M., Esteves, L.S., Furmanczyk, K., Haerens, P., Matias, A., Perini, L., Taborda, R., Terefenko, P., Trifonova, E., Trouw, K., Valchev, N., Van Dongeren, A., Van Koningsveld, M., Williams, J.J., 2009. Coastal storm risk assessment in Europe: examples from 9 study sites. J. Coast. Res. 1632-1636.

Garnier, E., Ciavola, P., Spencer, T., Ferreira, O., Armaroli, C., McIvor, A., 2017. Historical analysis of storm events: case studies in France, England, Portugal and Italy. Coast. Eng. http://dx.doi.org/10.1016/j.coastaleng.2017.06.014.

Haigh, I.D., Wadey, M.P., Gallop, S.L., Loehr, H., Nicholls, R.J., Horsburgh, K., Brown, J.M., Bradshaw, E., 2015. A user-friendly database of coastal fl ooding in the United Kingdom from 1915 - 2014. Sci. Data 2 (150021), 1-13. http://dx.doi.org/ 10.1038/sdata.2015.21.

Harley, M.D., Turner, I.L., Short, A.D., Ranasinghe, R., 2010. Interannual variability and controls of the Sydney wave climate. Int. J. Climatol. 30 (9), 1322-1335. http:// dx.doi.org/10.1002/joc.1962.

Harley, M.D., Valentini, A., Armaroli, C., Perini, L., Calabrese, L., Ciavola, P., 2016. Can an early-warning system help minimize the impacts of coastal storms? A case study of the 2012 Halloween storm, northern Italy. Nat. Hazards Earth Syst. Sci. 16, 209-222. http://dx.doi.org/10.5194/nhess-16-209-2016.

Lamb, H., Frydendahl, K., 1991. Historic storms of the north sea, british Isles, and Northwest Europe. Int. J. Climatol. http://dx.doi.org/10.1002/joc.3370120610.

Llasat, M.C., Llasat-Botija, M., López, L., 2009. A press database on natural risks and its application in the study of floods in Northeastern Spain. Nat. Hazards Earth Syst. Sci. 9, 2049-2061. http://dx.doi.org/10.5194/nhess-9-2049-2009.

Lozano, I., Devoy, R.J.N., May, W., Andersen, U., 2004. Storminess and vulnerability along the Atlantic coastlines of Europe: analysis of storm records and of a greenhouse gases induced climate scenario. Mar. Geol. 210, 205-225. http://dx.doi.org/ 10.1016/j.margeo.2004.05.026.

Martinez, G., Armaroli, C., Costas, S., Harley, M.D., Paolisso, M., 2017. Experiences and Results from Interdisciplinary Collaboration: Utilizing Qualitative Information to Formulate Disaster Risk Reduction Measures for Coastal Regions. http://dx.doi.org/ 10.1016/j.coastaleng.2017.09.010. This issue).

Perini, L., Calabrese, L., Salerno, G., Ciavola, P., Armaroli, C., 2016. Evaluation of coastal vulnerability to flooding: comparison of two different methodologies adopted by the Emilia-Romagna region (Italy). Nat. Hazards Earth Syst. Sci. 16 http://dx.doi.org/ 10.5194/nhess-16-181-2016.

Pfister, C., Garnier, E., Alcoforado, M.J., Wheeler, D., Luterbacher, J., Nunes, M.F. Taborda, J.P., 2010. The meteorological framework and the cultural memory of three severe winter-storms in early eighteenth-century Europe. Clim. Change 101, 281-310. http://dx.doi.org/10.1007/s10584-009-9784-y.

Porcu, F., Carrassi, A., 2009. Toward an estimation of the relationship between cyclonic structures and damages at the ground in Europe. Nat. Hazards Earth Syst. Sci. 9 , 823-829. http://dx.doi.org/10.5194/nhess-9-823-2009.

Ribera, P., Gallego, D., Pena-Ortiz, C., Del Rio, L., Plomaritis, T.A., Benavente, J., 2011. Reconstruction of Atlantic historical winter coastal storms in the Spanish coasts of the Gulf of Cadiz, 1929-2005. Nat. Hazards Earth Syst. Sci. 11, 1715-1722. http:// dx.doi.org/10.5194/nhess-11-1715-2011.

Sekovski, I., Armaroli, C., Calabrese, L., Mancini, F., Stecchi, F., Perini, L., 2015. Coupling scenarios of urban growth and flood hazards along the Emilia-Romagna coast (Italy). Nat. Hazards Earth Syst. Sci. 15, 2331-2346. http://dx.doi.org/10.5194/nhess-152331-2015. 
Sotillo, M.G., Aznar, R., Valero, F., 2006. Mediterranean offshore extreme wind analysis from the 44-year HIPOCAS database: different approaches towards the estimation of return periods and levels of extreme values. Adv. Geosci. 7, 275-278. http:// dx.doi.org/10.5194/adgeo-7-275-2006.

Spencer, T., Brooks, S.M., Evans, B.R., Tempest, J.A., Moller, I., 2015. Southern North Sea storm surge event of 5 December 2013: water levels, waves and coastal impacts. Earth-Science Rev. 146, 120-145. http://dx.doi.org/10.1016/ j.earscirev.2015.04.002.

Twigg, J., 2015. Disaster Risk Reduction. Good Practice Review 9. Overseas Development Institute, London, UK, p. 382.

Uppala, S.M., Kallberg, P.W., Simmons, A.J., Andrae, U., Bechtold, V.D., Fiorino, M., Gibson, J.K., Haseler, J., Hernandez, A., Kelly, G.A., Li, X., Onogi, K., Saarinen, S. Sokka, N., Allan, R.P., Andersson, E., Arpe, K., Balmaseda, M.A., Beljaars, A.C.M., Van De Berg, L., Bidlot, J., Bormann, N., Caires, S., Chevallier, F., Dethof, A.,
Dragosavac, M., Fisher, M., Fuentes, M., Hagemann, S., Holm, E., Hoskins, B.J., Isaksen, L., Janssen, P.A.E.M., Jenne, R., McNally, A.P., Mahfouf, J.F., Morcrette, J.J., Rayner, N.A., Saunders, R.W., Simon, P., Sterl, A., Trenberth, K.E., Untch, A., Vasiljevic, D., Viterbo, P., Woollen, J., 2005. The ERA-40 re-analysis. Q. J. R.

Meteorol. Soc. 131, 2961-3012. http://dx.doi.org/10.1256/qj.04.176.

Van Dongeren, A.R., Ciavola, P., Viavattene, C., De Kleemaker, S., Martinez, G., Ferreira, O., Costa, C., McCall, R., 2014. RISC-kit: resilience-increasing strategies for coasts-toolkit. J. Coast. Res. SI 70, 366-371. http://dx.doi.org/10.2112/SI70-062.1.

Van Dongeren, A., Ciavola, P., Martinez, G., Viavattene, C., De Kleemaker, S., Ferreira, O. Costa, C., McCall, R., 2017. RISC-KIT: resilience-increasing strategies for coasts. Coast. Eng. (in this issue).

Van Koningsveld, M., de Boer, G.J., Baart, F., Damsma, T.D., Heijer, K., Van Geer, P., de Sonneville, B., 2010. OpenEarth: inter-company management of data, models, tools and knowledge. In: WODCON XIX Conference. Beijing. 